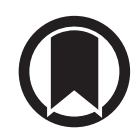

CrossMark

\section{Idiopathic interstitial pneumonia or idiopathic interstitial pneumonitis: what's in a name?}

To the Editor:

We read with interest the recently published perspective in the European Respiratory Journal by WeLLS et al. [1], "What's in a name? That which we call IPF, by any other name would act the same." Although there is also concern regarding the term "idiopathic" for idiopathic pulmonary fibrosis [2], there is more concern regarding the term "pneumonia" for the family of idiopathic interstitial pneumonias.

"Pneumonitis" (term derived from the Greek "pneumon", meaning lung, and the suffix "-itis", meaning inflammation) is a term used to describe inflammation of the lung tissue (alveoli, interstitium or both) due to factors other than microorganisms [3,4], whereas "pneumonia" is defined as an acute inflammatory process combined with consolidation and exudation caused by an infection. The main distinguishing features between pneumonitis and pneumonia are thus based on aetiological and pathological characteristics [3-5]. While pneumonitis and pneumonia are often used synonymously, pneumonitis is typically used when the cause is a noninfectious agent (such as a chemical or radiation) $[6,7]$.

In the American Thoracic Society/European Respiratory Society international multidisciplinary consensus classification of the idiopathic interstitial pneumonias published in 2002, it is stated that "Idiopathic indicates unknown cause and interstitial pneumonia refers to involvement of the lung parenchyma by varying combinations of fibrosis and inflammation, in contrast to airspace disease typically seen in bacterial pneumonia", and that "For the purposes of this document, the following terms are viewed as synonymous: idiopathic and cryptogenic as well as pneumonia and pneumonitis" [8]. Since then, the term "idiopathic interstitial pneumonias" (IIPs) has taken over, and in fact, for the various diffuse parenchymal lung diseases (with the exception of hypersensitivity pneumonitis and radiation pneumonitis), we use the term "pneumonia" instead of "pneumonitis" even to define new entities, such as "interstitial pneumonia with autoimmune features" [9]. This terminology was kept in the last update of the International Multidisciplinary Classification of the Idiopathic Interstitial Pneumonias [10], although there were suggestions for changing the term "pneumonias".

The term "pneumonia" in the interstitial disorders was first introduced by pathologists and the consequent pathological classifications of interstitial disorders adopted this term, although the histopathological (and microbiological) features of the various interstitial disorders clearly indicated the inappropriateness of this term [11, 12]. IIPs are an important subset of the broad group of diffuse interstitial (parenchymal) lung diseases. Common to all IIPs is the expansion and potential distortion of distal lung interstitium by some combination of inflammation and/or fibrosis within each IIP, with idiopathic pulmonary fibrosis (IPF) and cryptogenic organising pneumonia representing the two extremes of interstitial and intraluminal injury, respectively.

The cardinal question is what sort of valid content we put into these two terms. If by "pneumonitis", we mean inflammation of the lung tissue (including the alveoli, bronchioles or interstitium, or all three in various grades) irrespective the presence of an infection, as used in other terms like hepatitis, vasculitis or nephritis, then we should use the term "pneumonitis" instead of "pneumonia" for the IIPs. To match this, one could suggest the terms "idiopathic nonspecific interstitial pneumonitis", "acute interstitial pneumonitis", "desquamative interstitial pneumonitis", "idiopathic lymphocytic interstitial pneumonitis", "unclassifiable idiopathic interstitial pneumonitis", "cryptogenic organising pneumonitis" and so forth.

@ERSpublications

The term "idiopathic interstitial pneumonitis" should be preferred to "idiopathic interstitial pneumonia” http://ow.ly/xiu030kOyIb

Cite this article as: Kolilekas L, Costabel U, Tzouvelekis A, et al. Idiopathic interstitial pneumonia or idiopathic interstitial pneumonitis: what's in a name? Eur Respir J 2019; 53: 1800994 [https://doi.org/ 10.1183/13993003.00994-2018]. 
In this context, we launch a proposal for discussion and eventually, an international consensus meeting addressing the nomenclature of IIPs (i.e. substitution of the term "pneumonia" with the term "pneumonitis"), in order to correctly distinguish and characterise the wide group of diffuse parenchymal pulmonary disorders.

Lykourgos Kolilekas ${ }^{1}$, Ulrich Costabel ${ }^{2}$, Argyris Tzouvelekis ${ }^{3}$, Vassilios Tzilas ${ }^{3}$ and Demosthenes Bouros ${ }^{3}$

${ }^{1} 7$ th Dept of Pneumonology, Hospital for Chest Diseases "Sotiria", Athens, Greece. ${ }^{2}$ Universitätsklinik, Essen, Germany.

${ }^{3} 1$ st Dept of Pneumonology, Medical School, National and Kapodistrian University of Athens, Hospital for Chest Diseases "Sotiria", Athens, Greece.

Correspondence: Demosthenes Bouros, Hospital for Chest Diseases "Sotiria", Messogion 152, Athens 11527, Greece. E-mail: debouros@med.uoa.gr

Received: May 282018 | Accepted: May 292018

Conflict of interest: None declared.

\section{References}

1 Wells AU, Brown KK, Flaherty KR, et al. What's in a name? That which we call IPF, by any other name would act the same. Eur Respir J 2018; 51: 1800692.

2 Wolters PJ, Blackwell TS, Eickelberg O, et al. Time for a change: is idiopathic pulmonary fibrosis still idiopathic and only fibrotic? Lancet Respir Med 2018; 6: 154-160.

Stedman's Medical Dictionary. 28th Edn. Philadelphia, Lippincott Williams \& Wilkins, 2006.

Dorland's Illustrated Medical Dictionary. 32nd Edn. Philadelphia, Elsevier Saunders, 2012.

Seaton D. Pneumonia. In: Seaton A, Seaton D, Leitch AG, eds. Crofton and Douglas's Respiratory Diseases. 5th Edn. Oxford, Blackwell Science Ltd, 2000; pp. 356-444.

6 Merriam-Webster. Pneumonitis. https://www.merriam-webster.com/dictionary/pneumonitis. Date last updated: June 3, 2018.

7 Merriam-Webster. Pneumonia. https://www.merriam-webster.com/dictionary/pneumonia. Date last updated: June $28,2018$.

8 American Thoracic Society, European Respiratory Society. American Thoracic Society/European Respiratory Society international multidisciplinary consensus classification of the idiopathic interstitial pneumonias. $A m$ J Respir Crit Care Med 2002; 165: 277-304.

9 Fischer A, Antoniou KM, Brown KK, et al. An official European Respiratory Society/American Thoracic Society research statement: interstitial pneumonia with autoimmune features. Eur Respir J 2015; 46: 976-987.

10 Travis WD, Costabel U, Hansell DM, et al. An official American Thoracic Society/European Respiratory Society statement: update of the international multidisciplinary classification of the idiopathic interstitial pneumonias. Am J Respir Crit Care Med 2013; 188: 733-748.

11 Liebow AA, Carrington CB. The interstitial pneumonias. In: Simon M, Potchen EJ, LeMay M, eds. Frontiers of Pulmonary Radiology. 1st Edn. New York, Grune \& Stratton, 1969; pp. 102-141.

12 Katzenstein ALA. Katzenstein and Askin's Surgical Pathology of Nonneoplastic Lung Disease. Philadelphia, W.B. Saunders, 1997.

From the authors:

We congratulate L. Kolilekas and co-workers on their closely argued plea to resolve semantic imprecision in a field that suffers from a surfeit of acronyms. We can only agree that the "idiopathic interstitial pneumonia" (IIP) label should be discussed forensically. Meaningful reappraisal of IIP terminology requires a major international initiative with, crucially, the presentation of arguments for proposed change to all group members with the opportunity for written responses, in advance of face to face discussion. This model is seldom applied in expert group discussions, which are sometimes perfunctory due to time constraints, especially when held during major world meetings. The current proposal can be seen as the correct initiation of changes that are likely to be hotly debated due to a pivotal difficulty, discussed below.

However, it is first of all worth clarifying that opposition to an immediate renaming of idiopathic pulmonary fibrosis (IPF) is based on considerations that do not necessarily apply to the IIP conundrum. Recent

@ERSpublications

We welcome debate on the implications of a change from "pneumonia" to "pneumonitis", but suggest that this alteration does not capture a unifying pathogenetic basis for these diverse disorders http://ow.ly/yMIA30ns2q0

Cite this article as: Wells $\mathrm{AU}$, Brown $\mathrm{KK}$, Flaherty $\mathrm{KR}$, et al. Idiopathic interstitial pneumonia or idiopathic interstitial pneumonitis: what's in a name? Eur Respir J 2019; 53: 1801939 [https://doi.org/ 10.1183/13993003.01939-2018]. 
advances in our field have not been built on a conceptual definition of IIP, but on resolution of confusion in the definition of the term "IPF". In clinical practice, treatment is not based upon a "diagnosis" of IIP. The proposed change from "pneumonia" to "pneumonitis" may have major conceptual implications but is minimal in scope, with no change in the IIP acronym. It is difficult to argue that the proposed change in IIP nomenclature suffers from the same practical drawbacks as those that are likely to apply to renaming IPF.

The prevailing difficulty is that the true clinical value of grouping the IIPs lies, not in similarities in pathogenesis and management, but in the recognition of diagnostic dilemmas arising from their overlapping clinical and radiological presentations. Is there any conceivable terminology that effectively unifies the pathogenetic heterogeneity of these disorders? For example, use of the term "pneumonitis" may, as argued by L. Kolilekas and co-workers, be a far more accurate statement of pivotal underlying mechanisms in most IIPs. But is this truly the case with regard to IPF, the most prevalent IIP? Have we not moved away from IPF disease models built on the concept of evolution from inflammation to fibrosis? Furthermore, can it be argued that infection is not a core part of IPF pathogenesis, in view of the current view of the disease as "idiopathic" and recent data relating to linkages between IPF progression and the nature of the respiratory microbiome?

We suggest that to create a framework for what is to remain an ongoing debate, there needs to be consensus on the purpose of a unifying IIP label. The practical value of disease classification may lie either in clinical utility or in the facilitation of pathogenetic insights. This seems self-evident, but in some cases, both goals are worthwhile but cannot be reconciled by means of terminological manoeuvres. In the case of the IIPs, the proposed basis for change is essentially pathogenetic but as discussed briefly above, these disorders do not have a unifying pathogenesis. Therefore, we suggest that the current value of the IIP term lies in clinical utility with a regard to an "IPF clinical syndrome", which gives rise to major diagnostic dilemmas in IPF and in idiopathic disorders other than IPF. The change proposed by L. Kolilekas and co-workers does not address this pivotal point. We should first of all reach agreement on the goal we are trying to achieve in making classification changes.

Finally, it is perhaps worth highlighting that in arguing for the entity of a progressive fibrotic phenotype in our recent perspective [1], we were acutely aware of the need for a term that captured both potential unifying pathogenetic pathways and a specific clinical problem (inexorable IPF-like progression despite usual treatment) that was common to patients falling into this subgroup. Extending this principle, we suggest that to be worthwhile, a change in the IIP label should ideally have important advantages for both domains.

Athol U. Wells ${ }^{1}$, Kevin K. Brown ${ }^{2}$, Kevin R. Flaherty ${ }^{3}$, Martin Kolb $\oplus^{4}$ and Victor J. Thannickal ${ }^{5}$ on behalf of the IPF Consensus Working Group ${ }^{6}$

${ }^{1}$ Interstitial Lung Disease Unit, Royal Brompton Hospital, London, UK. ${ }^{2}$ National Jewish Health, Denver, CO, USA. ${ }^{3}$ University of Michigan Health System, Ann Arbor, MI, USA. ${ }^{4}$ Dept of Respiratory Medicine, Pathology and Molecular Medicine, McMaster University, Hamilton, ON, Canada. ${ }^{5}$ Division of Pulmonary, Allergy and Critical Care Medicine, University of Alabama at Birmingham, Birmingham, AL, USA. ${ }^{6} \mathrm{~A}$ list of members of the IPF Consensus Working Group can be found at the end of this article.

Correspondence: Athol U. Wells, Royal Brompton Hospital, Sydney St, Chelsea, London SW3 6HP, UK. E-mail: rbhild@rbht.nhs.uk

Received: Oct 092018 | Accepted after revision: Jan 242019

The IPF Consensus Working Group: K.M. Antoniou, J. Behr, P.B. Bitterman, C.D. Cool, U. Costabel, T.V. Colby, V. Cottin, B. Crestani, G.P. Downey, J. Gauldie, S.D. Groshong, A. Guenther, J.C. Horowitz, Y. Inoue, J.A. Lasky, A.H. Limper, D.A. Lynch, F.J. Martinez, J.L. Myers, A.G. Nicholson, I. Noth, V. Poletti, C.J. Ryerson, J.H. Ryu, D. Valeyre, C. Vancheri and E.S. White.

Conflict of interest: A.U. Wells reports personal fees for consultancy and lecturing from Intermune/Roche, Boehringer Ingelheim and Bayer, and personal fees for consultancy from Gilead, outside the submitted work. K.K. Brown reports multiple lung fibrosis grants from NHLBI, personal fees from AstraZeneca, Biogen, Fibrogen, Galecto, Gilead, MedImmune, Novartis, Aeolus, ProMetic, Patara, Third Pole, aTyr, Galapagos and Boehringer Ingelheim, has a submitted grant with Roche/Genentech, and conversation under CDA only with Global Blood Therapeutics and Genoa, outside the submitted work. K.R. Flaherty reports grants and personal fees from Boehringer Ingelheim and Roche/ Genentech, grants from Afferent, and personal fees from Veracyte, Fibrogen, Immuneworks, Aeolus, Pharmakea, Sanofi-genzyme and Celgene, outside the submitted work. M. Kolb reports grants and personal fees from Roche, Boehringer Ingelheim, GSK and Prometic, personal fees from Gilead and Genoa, and grants from Actelion, Respivert, Alkermes and Pharmaxis, outside the submitted work. V.J. Thannickal has nothing to disclose.

\section{Reference}

1 Wells AU, Brown KK, Flaherty KR, et al. What's in a name? That which we call IPF, by any other name would act the same. Eur Respir J 2018; 51: 1800692. 